\title{
DETECTION OF SPECIFIC CAUSES OF TUBERCULOSIS IN THE DAIRY CATTLE OF BANGLADESH AGRICULTURAL UNIVERSITY BY SEQUENCING AND SEQUENCE ANALYSIS
}

\author{
A. Yasmin, M. Z. Hossain, U. K. Rima, T. Ruba and M. A. H. N. A. Khan*
}

Department of Pathology, Faculty of Veterinary Science, Bangladesh Agricultural University, Mymensingh-2202, Bangladesh.

\begin{abstract}
Tuberculosis (TB) is a chronic disease of man and animal. In this study intradermal tuberculin test, necropsy, histopathology, polymerase chain reaction (PCR) and sequencing techniques were used to diagnose specific cause of TB in dairy cattle of Bangladesh Agricultural University, Mymensingh. Intradermal tuberculin tests were carried out on randomly selected 100 dairy cattle. Tuberculin test positive cattle $(\mathrm{N}=05)$ were examined at necropsy and granulomas in lungs was seen in three cattle. Caseous necrosis and swelling of lymphnodes was seen in prescapular $(\mathrm{N}=01)$ and mesenteric $(\mathrm{N}=02)$ lymphnodes. In a case nodular lesion was seen in lungs and mesenteric lymphnodes. Portion of infected lungs and lymphnodes were snap frozen, extracted genomic DNA and PCR protocols was adapted targeting MPB83 gene. Result of PCR showed amplification of $600 \mathrm{bp}$ fragments in five cases. The MPB83 gene although specific for M. Bovis, the gene is less abundantly expressed by M. tuberculosis. To differentiate infectivity due to M. Bovis and M. Tuberculosis, two more PCR were adapted targeting pncA and oxyR genes. Out of five cattle tested in PCR all samples generated pncA specific $185 \mathrm{bp}$ and oxyR gene specific $270 \mathrm{bp}$ amplicons. The sequencing of MPB83, pncA and oxyR genes were carried out. Results of sequencing did not show mutation in MPB83 gene. Sequencing of pncA gene showed replacement of nucleic acid base (guanine to cytosin) in position 169 in cattle no. 5. Similarly, sequence analysis of oxyR gene $(\mathrm{n}=05)$ showed replacement of nucleic acid base (adenine to guanine) in position 285 in cattle no. 5. The cattle no. 5 was confirmedly infected with M. Tuberculosis and rest of the cattle were infected with M. Bovis. The tuberculin tests, necropsy, histopathology and PCR amplification of MPB83 gene may not contribute species specific detection of Mycobacterial infectivity in cattle. Sequencing and sequence analysis of pncA and oxyR genes found to differentiate infectivity in cattle due to M. Bovis and M. Tuberculosis. Both of the bacterial species are extremely zoonotic and dairy cattle of Bangladesh Agricultural University were infected with both M. Bovis and M. Tuberculosis. It needs to tests all the dairy cattle twice in a year with tuberculin tests and dispose test reactors in order to minimize zoonotic risk.
\end{abstract}

Keywords: Dairy cattle, BTB, tuberculin test, Ziehl Neelsen staining, PCR, pncA, oxyR genes, MPB83 gene.

\section{INTRODUCTION}

Bovine tuberculosis (BTB) is a chronic debilitating disease of dairy animals, caused by intracellular acid-fast bacterium M. bovis (Ameni et al., 2007) and M. tuberculosis (Hossain et al., 2016). Tuberculosis (TB) remains a major cause of morbidity and mortality worldwide (Liebana et al., 1995). Bovine TB caused by M. bovis is member of $M$. tuberculosis complex (MTBC) and refers to a genetically related group of Mycobacterium species that can cause TB in men and animals. M. tuberculosis complex includes: M. tuberculosis, M. africanum, M. bovis and the Bacillus Calmette-Guérin strain, M. microti, M. canettii, M. caprae, M. pinnipedii and M. mung (Hamidou et al., 2006). Among them M. bovis and M. tuberculosis are common in men and dairy cattle (Ayele et al., 2004; Thoen et al., 2006; Yumi and Tooru, 2007). TB caused by M. tuberculosis (MTB) is a specific infectious cause of illness and death of human. In 2013, approximately 9 million people in the world developed active TB and 1.5 million die (WHO, 2014). These numbers are increasing globally, especially in Africa, China, India, Eastern Europe and the former Soviet Union (WHO, 2012). The human burden of TB caused by M. bovis is largely unknown (Garnier et al., 2003). In 2014, TB killed 1.5 million people (1.1 million HIV-negative and 0.4 million HIV-positive). Death toll comprised 890000 for men, 480000 for women and 140000 for children (WHO, 2015). In 2015, there were an estimated 10.4 million new (incident) TB cases worldwide, of which 5.9 million (56\%) were among men, 3.5 million (34\%) women and 1.0 million (10\%) children. People living with HIV accounted for 1.2 million (11\%) of all new TB cases. Six countries accounted for $60 \%$ of the new cases including India, Indonesia, China, Nigeria, Pakistan and South Africa and Bangladesh got 7th (WHO, 2016).

*Corresponding e-mail address: hadi.khan@bau.edu.bd 


\section{A. Yasmin and others}

It has been estimated that more than 50 million cattle are infected with $M$. bovis worldwide and that the resulting economic losses are approximately $\$ 3$ billion per year (Garnier et al., 2003). Literature available indicated that the occurrence of TB in cattle due to M. bovis and M. tuberculosis is common in many developing countries and due to lack of appropriate technology. Identification of the incidence of cattle TB is mostly ignored (Forrellad et al., 2013).

In developed countries pasteurization of milk and control of bovine tuberculosis (BTB) by test and slaughter based control measures have dramatically reduced the transmission of $M$. bovis infection from cattle to humans. M. bovis is now predominantly an occupational zoonosis with potential risk for workers on farms, in abattoirs, and in zoos (Dalovisio et al., 1992; Hossain et al., 2016). Bovine TB has got a major impact on livestock productivity, and on the livelihoods of poor and marginalized communities. In 2015, there were an estimated 149000 cases of zoonotic TB in human (WHO, 2016). The scenario of zoonotic TB in Bangladeshi cattle is less defined.

Bangladesh is one of the highest TB burden countries; total human case notification in 2013 was 1, 90,891 and ranked seventh in terms of global occurrence of TB (WHO, 2014). Tuberculosis in cattle is mostly caused by M. bovis and in human is due to M. Tuberculosis; both of the organisms are transmissible between man and animals and are highly zoonotic. Now a day, the incidence of M. bovis in cattle is increased in Bangladesh (Hossain et al., 2016) and in human, the incidence of TB due to M. bovis is more than 35\% (Hewinson et al., 2006). Dairy industry in Bangladesh started rising but the incidence of TB due to M. bovis and M. Tuberculosis is largely unknown. Tuberculosis in elderly dairy cattle in farm condition is common and cross breed cattle are mostly susceptible (Hossain et al., 2016). The dairy farm of Bangladesh Agricultural University has got local and cross breed cattle and there were sporadic infectivity of cattle due to M. bovis and M. tuberculosis (Al Mamun et al., 2016). As tuberculosis is a slow growing infectious disease it is absolutely difficult to identify infected but symptomless cattle and thus infected cattle spreading diseases silently in farm cattle and human being working around. The Sustainable Development Goals (SDGs) for 2030 were adopted by the United Nations in 2015. One of the targets is to end the global TB epidemic. The WHO End TB Strategy, approved by the World Health Assembly in 2014, Detection of specific causes of tuberculosis in the dairy cattle calls for a $90 \%$ reduction in TB deaths and an $80 \%$ reduction in the TB incidence rate by 2030 , compared with 2015 (WHO 2016). The incidence of TB in animals in developing country including Bangladesh is largely unknown and may warn expanding TB. This study was, aimed at specific identification of TB in dairy cattle using tuberculin test, necropsy and histopathology. The rapid and accurate detection of Mycobacterium sp. is of paramount importance in the effective control and eradication of TB from dairy animals and human.

\section{MATERIALS AND METHODS}

\section{Selection of animals}

The dairy cattle were tested in the Bangladesh Agricultural University (BAU) dairy farms; histopathology and polymerase chain reaction (PCR) was carried out in the Department of Pathology, Faculty of Veterinary Science, BAU, Mymensingh. A total of 25 Holstein Frisian X local cross breed, 25 red Chittagong and 50 local breed cattle were tested using intradermal tuberculin test during the period between July 2014 to June 2015.

\section{Identification of $\mathrm{TB}$ test reactors}

A short needled syringe (McLintock ${ }^{\circledR}$ preset syringe and tuberculin testing equipment, Glasgow, G81 1NH) was used to perform intra-dermal tuberculin test in dairy cattle. The tuberculin test was performed onto the caudal fold of the tail and the mid-neck region according to the standard protocol of OIE (OIE, 2009).

The caudal fold was pinched up with the tip of fingers and its thickness was measured by callipers. The tuberculin (Bovituber) was injected in the caudal fold; injection site was examined for swelling and thickness as measured using callipers at every $24 \mathrm{hrs}$ of tuberculin injection until $72 \mathrm{hrs}$ post injection (Monaghan et al., 1994). A total of 100 $\mu$ l of Bovine PPD was injected within the dermis of the caudal tail fold using a short needled syringe. The test was read at 24, 48 and $72 \mathrm{hrs}$ (+/- $6 \mathrm{hrs)}$ after the tuberculin was administered. The injection site was inspected by both visual observation and palpation for indications that the animal has mounted an immune response to the PPD. The response was recognized by swelling or discoloration at the site where the PPD was injected. If any abnormalities such as discoloration or swelling are found at the injection site, the animal was classified as Caudal-fold Tuberculin Test (CFT) test responder (also known as suspect). If no response was noted, the animal was classified as CFT test-negative. 


\section{Differentiate Mycobacterium spp. using Comparative intradermal tuberculin test}

The Caudal-fold Tuberculin Test (CFTT) responder cattle to bovine PPD may mount immune response against a number of Mycobacterium species including M. Bovis, M. Tuberculosis, M. Avium sub-spp var paratuberculosis and M. avium. The Comparative intradermal tuberculin tests (CITT) were used as described in the OIE Manual of Diagnostic Tests and Vaccines for Terrestrial Animals were used to differentiate infectivity due to M. bovis/ tuberculosis and para TB. This investigation was carried out with the selected cattle test positive to CFTT. Two injection sites (neck region, up and down, $130 \pm 10 \mathrm{~mm}$ apart) were clipped, shaved and cleansed with spirit soaked cotton. A fold of skin within each clipped area was measured using callipers before injection. A short needled syringe (McLintock ${ }^{\circledR}$ preset syringe and tuberculin testing equipment, Glasgow, G81 1NH) were loaded with either avian or bovine type tuberculin and $0.1 \mathrm{ml}$ of the content was injected 7 days after SITT. The bovine type tuberculin was injected, into the lower clipped area while the avian type was injected into the upper clipped area on the same side of the mid-neck of cattle. The skin fold thickness of each injection site was measured 24, 48 and 72 hours after the injections. A case was considered positive while the skin reaction with bovine type tuberculin was $4 \mathrm{~mm}$ or more than that with the avian type tuberculin. An inconclusive result was recorded when the bovine reaction recorded between 1 and $4 \mathrm{~mm}$ but greater than the avian reaction. A negative result was recorded while the bovine reaction appeared negative or if the positive or inconclusive bovine reaction equal to or less than the avian reaction site.

\section{Pathological investigation of tuberculin test positive cattle}

The routine necropsy was done on the tuberculin test responder cattle in the BAU Dairy Farm, Mymensingh. The tuberculin test positive cattle $(\mathrm{N}=05)$ were euthanized by intravenous injection of saturated $\mathrm{MgSO}_{4}$ solution and a thorough post-mortem examination was carried out. At necropsy, gross tissue changes were observed and recorded carefully. Personal protection was taken not to get infected. The lungs, thoracic, prescapular, prefemoral and mesenteric lymphnodes were examined carefully. The organs were sectioned $1 \mathrm{~cm}$ apart to visualised nodular lesions if any. Representative sections of lungs and lymphnodes were collected in $10 \%$ neutral buffered formalin for the histopathological study. The tissue sections of lungs and lymphnodes were stained with Hematoxylin and eosin (H\&E) and Ziehl Neelsen staining (Luna, 1968). Portion of lungs and lymphnodes were snap frozen, extracted DNA for PCR detection of specific of TB in cattle.

\section{PCR detection of specific cause of TB in cattle}

Most of the mycobacterium localized in the epithelial cells, macrophages, lymphocytes and neutrophils of infected tissues and these cells serve as the unique source of Mycobacterial DNA. The lungs and lymphnodes showed granulomatous lesions were retrieved from liquid nitrogen and used in DNA extraction. The lungs and lymphnodes were crushed in liquid nitrogen and extracted DNA using the phenol-chloroform-isoamyl (PCI) alcohol and ethanol precipitation method (Labony et al., 2014). The purity and concentration of extracted DNA were determined by agar gel electrophoresis and spectrophotometric analysis. The absorbance of the extracted DNA was measured at $\mathrm{A}^{260}$ and $\mathrm{A}^{280}$. The DNA concentration obtained were ranged between $200 \mathrm{ng}$ to $350 \mathrm{ng} / \mu \mathrm{l}$. The extracted DNA was further diluted in nuclease free water at a concentration of $100 \mathrm{ng} / \mu \mathrm{l}$ and stored at $-20^{\circ} \mathrm{C}$ until PCR was carried out.

The PCR protocols adapted targeting three important genes to identify and differentiate infectivity due to $M$. tuberculosis and M. bovis. DNA from the BCG vaccine strain was used in PCR reactions as positive control for $M$. bovis. Three sets of PCR were carried out targeting MPB83, pncA and oxyR genes (Table 1). The reaction was carried out in $25 \mu 1$ volume in the thin walled PCR tubes. The promega TNC PCR Master Mix Kit (2x) was used to amplify genomic DNA in a programmable thermocycler (Eppendorf, Germany). Three sets of PCR primers 20pol/ reactions was used. A total of 32 cycles of PCR amplification was carried out (Table 2) and the amplicons were electrophoresed in $1.5 \%$ agarose gel. The images were captured by using a gel documentation system (Cell Biosciences, Alphalmager HP, USA).

Sequencing of MPB83, pncA and oxyR genes to identify specific cause of TB

The fragments of MPB83 (600bp), pncA (185bp) and oxyR (270bp) genes as amplified in PCR were gel cleaned using the Wizard® SV Gel and PCR Clean-Up System (Promega, USA). The PCR product (50 $\mu$ l) was electrophoresed and the band corresponding to the DNA of interest was located against long-wavelength ultraviolet light. Using a sterile scalpel and blade the segment of the gel containing the band of interest was cut 


\section{A. Yasmin and others}

out, chopped and extracted (according to manufacturer instruction). Purified cDNA (50-75 $\mu$ l) of each gene was transferred to $0.5 \mathrm{ml} \mathrm{PCR} \mathrm{tube} \mathrm{separately} \mathrm{for} \mathrm{each} \mathrm{sample.} \mathrm{For} \mathrm{each} \mathrm{sample} \mathrm{forward} \mathrm{and} \mathrm{reverse} \mathrm{primer} \mathrm{(10poml)}$ were used. The cleaned cDNA along with its primers was shipped to AIT Biotech, Singapore for sequencing. The sequences obtained were analyzed with Basic local alignment system (BLAST) and nucleic acid bases at specific location were analysed. The nucleic acid sequences were aligned with other related sequences retrieved from the GenBank and the species of Mycobacterium involved were determined.

Table 1. The PCR primers used to amplify fragments of MPB83, pncA and oxyR genes of M. tuberculosis (MTB) and M. bovis (BTB)

\begin{tabular}{|c|c|c|c|}
\hline Primer name & Primer sequences $\left(5^{\prime}-3^{\prime}\right)$ & Amplicon size & References \\
\hline MPB83 F & cagggatccaccatgttcttagcgggttg & $600 \mathrm{bp}$ & Jiang et al., 2006 \\
\hline MPB83 R & tggcgaattc-ttactgtgecggggg & & \\
\hline pncAF (MTB) & atgcgggegttgatcatcgtc & & Monteros et al., 1998 \\
\hline $\begin{array}{l}\text { pncA R } \\
\text { MTB } \\
\text { BTB }\end{array}$ & cggtgtoccggagaagcog cggtotoccogagaagcco & $185 \mathrm{bp}$ & \\
\hline $\operatorname{oxyR} \mathrm{F}(\mathrm{MTB})$ & $\begin{array}{l}\text { cggtgtgecggagaagcegg cggtgtgecggagaagecg } \\
\text { tggecggggettcgegcgt }\end{array}$ & & \\
\hline $\begin{array}{l}\text { oxyR R } \\
\text { MTB } \\
\text { BTB }\end{array}$ & $\begin{array}{l}\text { gcacgacggtggccaggea } \\
\text { tgcacgacggtggccagga }\end{array}$ & $270 \mathrm{bp}$ & \\
\hline
\end{tabular}

Table 2. The thermal profiles used to amplify fragments of Mycobacterium genes

\begin{tabular}{|c|c|c|c|c|c|c|c|}
\hline \multirow{3}{*}{$\begin{array}{l}\text { Genes } \\
\text { targeted }\end{array}$} & \multirow{3}{*}{ Primers name } & \multicolumn{5}{|c|}{ Thermal profile } & \multirow[t]{3}{*}{ Reaction held } \\
\hline & & \multirow{2}{*}{$\begin{array}{c}\text { Initial } \\
\text { denaturation }\end{array}$} & \multicolumn{3}{|c|}{ PCR Cycles $(\mathrm{N}=32)$} & \multirow{2}{*}{$\begin{array}{c}\text { Final } \\
\text { Elongation }\end{array}$} & \\
\hline & & & Denaturation & Annealing & Elongation & & \\
\hline MPB83 & $\begin{array}{l}\text { MPB83 F } \\
\text { MPB83 R } \\
\end{array}$ & $98^{\circ} \mathrm{C}, 5 \mathrm{~min}$ & $95^{\circ} \mathrm{C}, 1 \mathrm{~min}$ & $56^{\circ} \mathrm{C}, 1 \mathrm{~min}$ & & \multirow{3}{*}{$72^{\circ} \mathrm{C}, 10 \mathrm{~min}$} & $4^{0} \mathrm{C}$ \\
\hline pncA & $\begin{array}{l}p n c A \mathrm{~F} \\
\text { pncA R }\end{array}$ & \multirow{2}{*}{$95^{\circ} \mathrm{C}, 12 \mathrm{~min}$} & \multirow{2}{*}{$94^{0} \mathrm{C}, 1 \mathrm{~min}$} & $67^{\circ} \mathrm{C}, 1 \mathrm{~min}$ & \multirow[t]{2}{*}{$72^{\circ} \mathrm{C}, 2 \mathrm{~min}$} & & \\
\hline $\operatorname{oxy} R$ & $\begin{array}{l}\text { oxyR F } \\
\text { oxyR R }\end{array}$ & & & $70^{\circ} \mathrm{C}, 1 \mathrm{mi}$ & & & \\
\hline
\end{tabular}

\section{RESULTS AND DISCUSSION}

Bovine tuberculosis (BTB) is an infectious disease of cattle and one of the biggest challenges facing the cattle farming industry today, particularly in Bangladesh (Ayele et al., 2004). It is caused by mostly due to bacterium M. bovis and also due to M. tuberculosis (Alam et al., 2012; Hossain et al., 2016). This study was carried out at the BAU Dairy farm and 100 adult cattle were tested using CFTT and CITT. Results of CFTT revealed skin thickening/ hypersensitivity in five cattle. The CIFT positive cattle were further tested with comparative tuberculin tests, none of the cattle appeared positive to avian PPD. Previously Al Mamun et al. (2016) used both the CFTT and CITT and none of the test cattle responded to avian PPD. Dairy cattle in Bangladesh were infected with bovine TB (M. bovis), human TB (M. tuberculosis) and para TB (M. avium sub$s p$ var paratuberculosis) and causing variable rate of morbidity and mortality (Hossain et al., 2016). By using CITT, infectivity in cattle due to avian TB can be differentiated from TB due to M. bovis and M. tuberculosis if there is swelling at both the injection sites (Al Mamun et al., 2016; Hossain et al., 2016). However, in this study, the CFTT responder cattle did not respond to avian PPD and the cattle $(\mathrm{N}=05)$ were assumed to be infected with either M. bovis or M. tuberculosis. Molecular test protocols like PCR and sequencing of specific genes are needed to ensure infectivity in cattle due to $M$. bovis and $M$. tuberculosis. The tuberculin test positive cattle $(\mathrm{N}=05)$ were, therefore, sacrificed by intravenous administration of saturated magnesium solution and further investigation was carried out. 
At necropsy ( $\mathrm{N}=03)$ the carcasses appeared very thin and paler $(\mathrm{N}=03)$, nodular masses was seen in the lungs (Figure 1a) of three tuberculin test positive cattle. Two cattle were appeared apparently healthy and the cattle had localized TB in mesenteric lymphnodes. The prefemoral $(\mathrm{N}=01)$ and mesenteric lymph nodes $(\mathrm{N}=02)$ were swollen in three cases (Figure 1b and 1c). In a case nodular lesions was seen both in the lungs and mesenteric lymphnodes. Caseous lesion was not seen in the prefemoral and thoracic lymphnodes of tuberculin test positive cattle. Tuberculosis in cattle caused granulomatous lesions in visceral organs (Al Mamun et al., 2016) and such lesions as seen at necropsy is indicative of Mycobacterial infectivity. To support the findings of this study, histopathological and PCR detection of specific causes of TB was carried out.
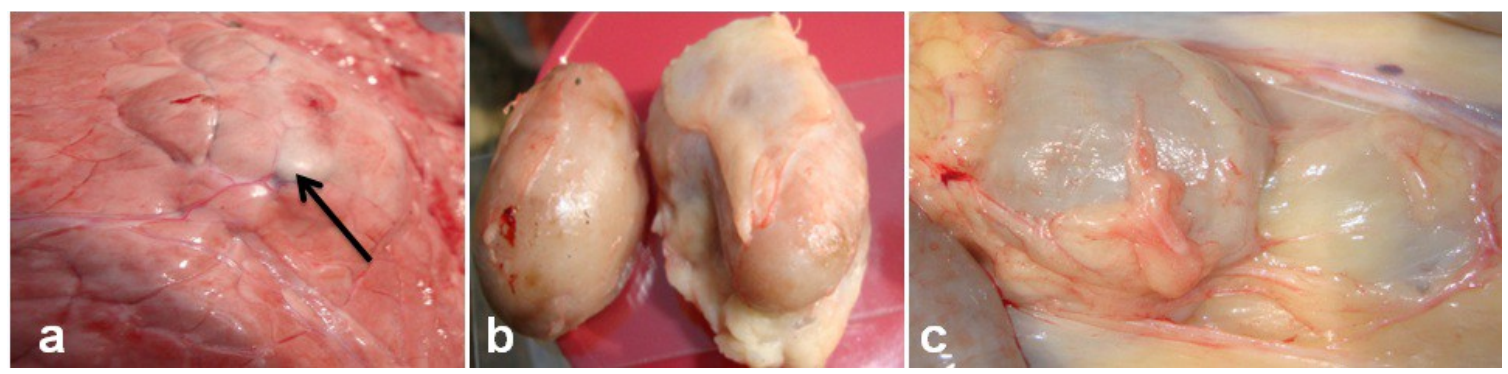

Figure 1. Lungs (a), prescapular lymph nodes (b) and mesenteric lymphnodes (c) obtained from Tuberculin test positive cattle. Nodular masses were seen in infected lungs (a, black arrow). The prescapular and mesenteric lymphnodes were enlarged and the capsule appeared tensed $(\mathrm{b} \& \mathrm{c})$.

Formalin fixed tissues sections were, therefore, stained with H\&E staining. Tissues sections of lungs and lymph nodes studied under microscope showed accumulation of macrophage and fibrin in lungs. Typical granulomas characterized by central core of caseous necrosis was not seen in lungs (Figure 2a) but were seen in lymphnodes (Figure 2b). The lungs lesions showed accumulation of macrophage, lymphocyte and fibrous connective tissue in the infected areas (Hossain et al., 2016). The gross and microscopic lesions seen in tuberculin test positive cattle were suspected to infect with Mycobacterium. The cause(s) of the granulomatous reaction in tissues was, therefore, detected by using Ziehl Neelsen staining. Tissue sections of lungs and lymphnodes while stained with Ziehl Neelsen staining showed acid fast bacteria (Figure 2c) in intracellular and extracellular state. The detection of acid fast organism in tissue section of lungs and lymphnodes is suggestive for Mycobacterial infectivity and may be due to M. bovis or M. tuberculosis (Alam et al., 2012; Hossain et al., 2016; Michel et al. 2007).
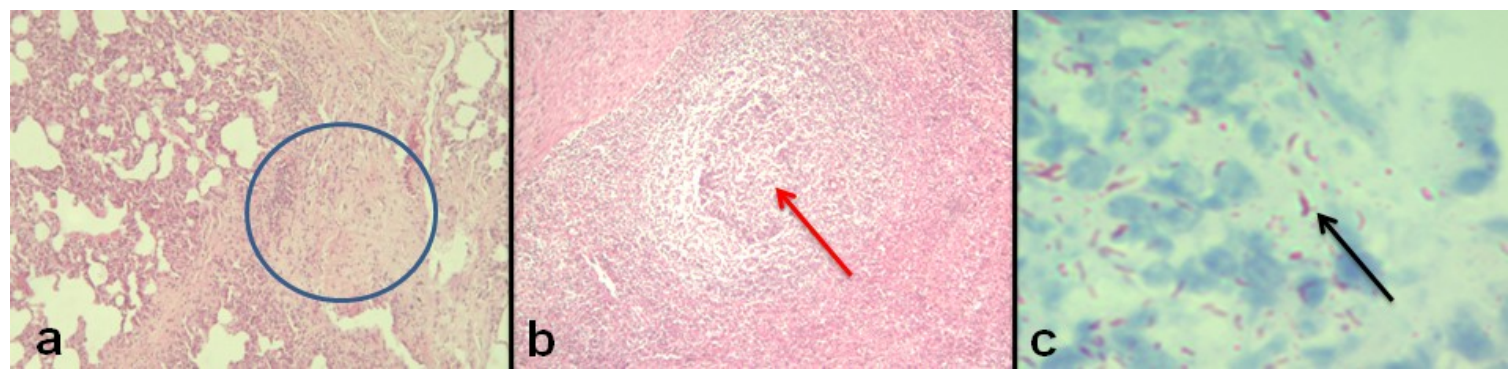

Figure 2. Sections of lungs (a) and lymphnode (b) obtained from tuberculin test positive cattle and stained with H\&E (10x). Accumulation of macrophage, lymphocytes and fibrin in tissue section of lungs of was seen. Sections of lymphnodes (b, arrow) showed granulomas consisting of central core caseous necrosis and peripheral infiltrations of monocytes and lymphocytes. Sections of lungs obtained from tuberculin test positive cattle and stained with Ziehl Neelsen stain showed pink color acid fast bacilli in the tissues (100x). 


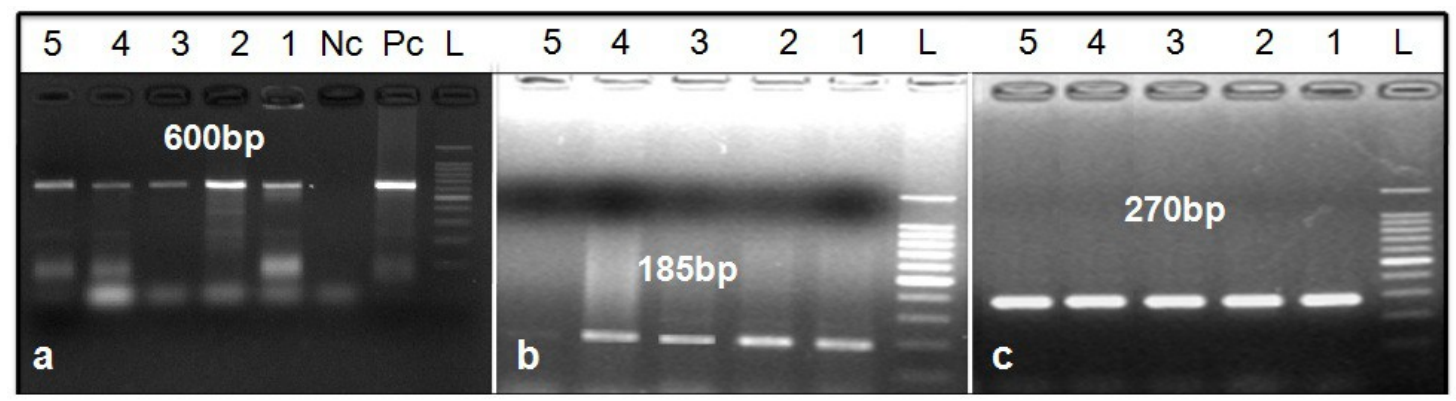

Figure 3. PCR detection of MPB83 (a), pncA (b) and oxyR (c) genes of Mycobacterial organisms. DNA extracted from the lungs and lymphnodes tuberculin test positive cattle showed the amplification of $600 \mathrm{bp}, 270 \mathrm{bp}$ and $185 \mathrm{bp}$ fragments of MPB83 (a), pncA (b) and oxyR (c) genes of Mycobacterium species respectively. The lane $\mathrm{L}$ is for 100bp ladder, $\mathrm{Pc}$ is for BCG vaccine DNA and Nc is for negative control. The lanes 1, 2, 3, 4 and 5 represent the test samples.

Tuberculin test reactivity, gross and microscopic changes in tissues and Ziehl Neelsen staining of tissue sections represent the cause of illness as Mycobacterium species, mostly due to either M. bovis or $M$. tuberculosis. The specific cause of tuberculosis in cattle was, therefore, confirmed by using species specific PCR. Initially a PCR was adapted to amplify fragment of MPB83 gene specific for M. bovis (Sreedevi et al., 2003; Jiang et al. 2006; Taylor et al. 2007). The extracted DNA (N=05) including BCG vaccine DNA found to amplify $600 \mathrm{bp}$ fragment in uniplex PCR (Figure 3a). MPB83 gene is critical for M. bovis but may also be shared by $M$. tuberculosis (Hossain et al., 2016). To differentiae infectivity of cattle TB due to M. tuberculosis and M. bovis two more PCR were adapted targeting pncA and oxyR genes (Table 1). The extracted DNA ( $\mathrm{N}=05$ ) while used in PCR found to generate 185bp and 270bp amplicons (Figure $3 \mathrm{~b}$ and 3c) suggestive for infectivity due to either $M$. tuberculosis or M. bovis. The specific cause of cattle TB due to M. tuberculosis and M. bovis was not confirmed by amplifying pncA and oxyR genes. In order to confirm further the specific cause of TB in cattle, the fragments of MPB83, pncA and oxyR genes were sequenced. Mutation in the fragments of MPB83 gene (600bp) was not seen at any time point and all the cattle samples tested in PCR found to contain similar base sequences in MPB83 gene. The polymorphisms in $p n c A$ and $\operatorname{oxy} R$ genes at specific loci are good indicator of specific infectivity due to M. bovis and M. tuberculosis (de los Monteros et al., 1998). Point mutation in the pncA (169 base point) and oxyR (285base point) genes are the indicator of infectivity due to either M. bovis or M. tuberculosis. Results of sequence analysis of pncA gene showed replacement of nucleic acid base (guanine to cytosin) in position 169 in a case (cattle No. 5). Similarly, sequence analysis of oxyR gene of the studied isolates showed replacement of nucleic acid base (adenine to guanine) in position 285 in the same case (cattle No. 5). The nucleic acid bases in pncA and oxyR genes of Mycobacterium species in cattle No. 1, 2, 3 and 4 differ greatly from cattle No. 5 . Analysis of the polymorphisms in the sequence of pncA and oxyR genes, it was confirmed that the cattle No. 5 of BAU dairy farm was infected with M. Tuberculosis and cattle 1,2,3 and 4 were infected with M. Bovis. The tuberculin tests, necropsy, histopathology, acid fast staining and PCR were successfully applied onto the cattle and samples collected from the cattle of BAU dairy farm. About $4 \%$ cattle were infected with M. bovis and $1 \%$ with M. tuberculosis. The PCR protocols and sequencing system adapted accurately identified infectivity due to M. bovis and M. tuberculosis.

\section{CONCLUSIONS}

To identify mycobacterial infectivity in cattle $(\mathrm{N}=100)$ intradermal tuberculin tests were carried out and five cattle appeared positive to both single intradermal tuberculin tests and comparative intradermal tuberculin tests but none of the cattle tested positive to avian PPD. At necropsy, tuberculous nodules in lungs and enlargement of lymphnodes $(\mathrm{N}=03)$ was seen but were not consistent in all cases. In a case tuberculous nodule in lungs and enlargement of lymphnodes were seen. Two tuberculin test positive cattle only showed enlargement of lymphnodes and lacking nodular lesion in lungs. The PCR protocols adapted amplified fragments of MPB83, pncA and oxyR genes. Mutation was not seen in the fragment of MPB83 gene sequenced and sequencing of MPB83 gene could not contribute specific detection of the cause of TB. The sequence analysis of pncA and 
oxyR genes indicated that four cattle were infected with M. bovis and one with M. tuberculosis. Both the $M$. bovis and M. tuberculosis are extremely zoonotic pathogens and differential infectivity in cattle can be achieved by amplifying and sequencing fragments of pncA and oxyR genes. Cattle of BAU dairy farm were infected with both the M. Bovis and M. Tuberculosis. It needs to test all the elderly dairy cattle with tuberculin tests twice in a year, disposed test positive cattle before spreading TB in other cattle and farmers working in the farm. Genomic DNA from the lungs or lymphnodes of tuberculin test positive cattle require to be tested in PCR, sequencing and sequence analysis for the detection of specific cause of TB and design future preventive strategy.

\section{ACKNOWLEDGEMENT}

Thanks are due to SPGR, BARC-NATP-Phase-1 for funding the research.

\section{REFERENCES}

1. Al Mamun MS, Ruba T, Hossain MZ, Pervin M and Khan MAHNA (2016). Evaluate comparative efficacy of tuberculin test, gross and histopathology, Ziehl-Neelsen staining and polymerase chain reaction technique for the detection of tuberculosis in dairy cattle. IOSR Journal of Agriculture and Veterinary Science (IOSRJAVS) 9: 25-31.

2. Alam M M, Islam MR, Hossain M Z, Islam M, Saha P C and Khan MAHNA (2012). Detection of mycobacterial infection from the lymphnode and lungs of suspected cattle using traditional and molecular technique. Bangladesh Journal of Progressive Science \& Technology 1: 077-080.

3. Ameni G, Aseffa A, Engers H, Young D, Gordon S and Hewinson G (2007). High prevalence and increased severity of pathology of bovine tuberculosis in Holsteins compared to zebu breeds under field cattle husbandry in central Ethiopia. Clinical Vaccine and Immunonization 14: 1356-1361.

4. Ayele WY, Neill SD, Zinsstag J, Weiss MJ and Pavlik I (2004). Bovine tuberculosis: an old disease but a new threat to Africa. Tubercle and Lung Disease 8: 924-937.

5. Dalovisio JR, Stetter M and Wells S (1992). Rhinorrhea: Cause of an airborne Mycobacterium bovis outbreak in zookeepers. Clinical Infectious Disease 15: 598-600.

6. De Los Monteros LEE, Galán JC, Gutiérrez SS, Marín JFG, Matín C, Dominguez L, Rafael L, Baquero F, Gómez-Mampaso E and Blásquez, J (1998). Allele-specific PCR method based on pncA and oxyR for distinguishing Mycobacterium bovis from Mycobacterium tuberculosis: Intraspecific M. bovis pncA sequence polymorphism. Journal of Clinical Microbiology 36: 239-242.

7. Forrellad M, Bianco M, Blanco F, Nunez J, Klepp L, Vazquez C, et al (2013). Study of the in vivo role of Mce2R, the transcriptional regulator of mce2 operon in Mycobacterium tuberculosis. BMC Microbiology 13: 200 .

8. Garnier T, Eiglmeier K, Camus JC, Medina N, Mansoor H, Pryor H, Duthoy S, Grondin S, Lacroix C, Monsempe C, Simon S, Harris B, Atkin R, Doggett J, Meyes R, Keating L, Wheeler PR, Parkhill J, Barrell BG, Cole ST, Gordon SV and Hewinson RG (2003). The complete genome sequence of Mycobacterium bovis. Proceeding of the National Academy of Science USA. 100: 7877-7882.

9. Hamidou T, Armand D, Isdore CS, Leen R and Françoise P (2006). Direct Detection of Mycobacterium tuberculosis Complex DNA and Rifampin Resistance in Clinical Specimens from Tuberculosis Patients by Line Probe Assay. Journal of Clinical Microbiology 44: 4384-4388.

10. Hewinson RG, Vordermeier HM, Smith NH and Gordon SV (2006). Recent advances in our knowledge of Mycobacterium bovis a feeling for the organism. Veterinary Microbiology 112: 127-139.

11. Hossain MZ, Rima UK, Islam MS, Habib MA, Chowdhury MGA, Saha PC, Chowdhury EH and Khan MAHNA (2016). Designing polymerase chain reaction (PCR) technique for the detection of specific causes of tuberculosis (TB) in dairy cattle and human. Journal of Veterinary Science \& Medical Diagnosis 5: 4.

12. Hossain MZ, Rima UK, Pervin M, Chowdhury GA, Habib MA, Haque ME, Chowdhury EH and Khan MAHNA (2012). Dept. of Pathology, BAU, Mymensingh. Application of Intra-Dermal Tuberculin and Polymerase Chain Reaction (PCR) Tests for the Detection of Tuberculosis in Dairy Cattle of Selected Areas in Bangladesh. Bangladesh Journal of Progressive Science and Technology 1: 085-088. 
13. Jiang XY, Wang CF, Wang CF, Zhang PJ and He ZY (2006). Cloning and Expression of Mycobacterium bovis Secreted Protein MPB83 in Escherichia coli. College of Biotechnology, Jilin Agricultural University, Changchun 130 118, China. Journal of Biochemical and Molecular Biology 39: 22-5.

14. Labony SS, Begum N, Rima UK, Chowdhury MGA, Hossain MZ, Habib MA and Khan MAHNA (2014). Apply traditional and molecular protocols for the detection of carrier state of visceral leishmaniasis in black Bengal goat. IOSR Journal of Agriculture and Veterinary Science (IOSR-JAVS) 7: 13-18.

15. Liebana E, Aranaz A, Mateos A, Vilafranca M and Gomez-Mampaso E (1995). Simple and rapid detection of Mycobacterium tuberculosis complex organisms in bovine tissue samples by PCR. Journal of Clinical Microbiology 33: 33-36.

16. Michel AL, Klerk LD, Pittus NG, Warren RM and Helden PV (2007). Bovine tuberculosis in African buffaloes: observations regarding Mycobacterium bovis shedding into water and exposure to environmental mycobacteria. BMC Veterinary Research 3: 23.

17. Monaghan ML, Doherty ML, Collins JD, Kazda JF and Davis WC (1994). The tuberculin tests. Veterinary Microbiology 40: 111-124.

18. Office International des Epizooties (OIE) 2009: Bovine Tuberculosis In: Manual of Standards: List B Diseases. International Des Epizooties 1-9.

19. Scorpio A and Zhang Y (1996). Mutations in pncA, a gene encoding pyrazinamidase/nicotinamidase, cause resistance to the antituberculous drug pyrazinamide in tubercle bacillus. Nature Medicine 2: 662-667.

20. Sreedevi B and Krishnappa G (2003). Detection of Mycobacterium tuberculosis complex organisms in clinical samples of cattle by PCR and DNA probe methods. Indian Journal of Comparative Microbiology, Immunology and Infectious Disease 24: 167-171.

21. Sreevatsan S, Escalante P, Pan X, Gillies DA, Siddidqui HS, Khalaf CN, Kreiswirth BN, Bifani P, Adams LG, Ficht T, Perumaalla VS, Cave MD, Embden JDN, and Musser JM (1996). Identification of a polymorphic nucleotide in oxyR specific for Mycobacterium bovis. Journal of Clinical Microbiology 34: 2007-2010.

22. Sreevatsan S, Pan S, Zhang Y, Deretic V and Musser JM (1997). Analysis of the oxyR-ahpC region in isoniazid-resistant and susceptible Mycobacterium tuberculosis complex organisms recovered from diseased humans and animals in diverse localities. Antimicrobial Agents and Chemotherapy 41: 600-606.

23. Taylor GM, Worth DR, Palmer S, Jahans K and Hewinson RG (2007). Rapid detection of Mycobacterium bovis DNA in cattle lymph nodes with visible lesions using PCR. BMC Veterinary Research 13: 12.

24. Thoen C, LoBue P, DeKantor I 2006: The importance of Mycobacterium bovis as a zoonosis. Veterinary Microbiology 112: 339-345.

25. WHO 2012, WHO policy on collaborative TB/HIV activities. Guidelines for national programmes and other stakeholders, World Health Organization, 20 Avenue Appia, 1211 Geneva 27, Switzerland. www.who.int.

26. WHO 2014. Global Tuberculosis report 2014. World Health Organization, 20 Avenue Appia, 1211 Geneva 27, Switzerland. www.who.int.

27. WHO 2015, Global Tuberculosis report 2015. 20th edition. World Health Organization, 20 Avenue Appia, 1211 Geneva 27, Switzerland. www.who.int.

28. WHO 2016. Global actions and investments fall far short of those needed to end the global TB epidemic. Global Tuberculosis report 2016. World Health Organization, 20 Avenue Appia, 1211 Geneva 27, Switzerland. www.who.int.

29. Yumi U and Tooru M (2007). Tuberculosis as a zoonosis. From a veterinary perspective. Comparative Immunology and Infectious Disease 30: 415-425. 